\title{
Projeto de Unidades Móveis de Atendimento Tecnológico às Micro e Pequenas Empresas
}

Recentemente foi criado um programa especial de apoio à micro e pequenas empresas na área de transformação de plásticos no Estado de São Paulo. Este programa é conhecido como PRUMO, Projeto Unidades Móveis, e foi criado através de uma parceria entre o IPT, o INP e SEBRAE-SP, contando com $o$ apoio financeiro da FAPESP. Considerando o caráter inovador deste programa e certamente o interesse da comunidade industrial de transformadores de plásticos, a revista Polímeros: Ciência \& Tecnologia resolveu entrevistar o Dr. Vicente Nelson Giovani Mazzarella, responsável pela direção deste programa, para prestar maiores esclarecimentos sobre o mesmo aos seus leitores.

Em poucas palavras, em que consiste o projeto PRUMO?

PRUMO quer dizer "Projeto Unidades Móveis". Através dele são realizados atendimentos tecnológicos, com o auxílio de Unidades Móveis que são laboratórios montados sobre furgões que contam com equipamentos para a maior parte dos ensaios básicos e com uma equipe constituída por um engenheiro especializado e um técnico, com amplo conhecimento em matérias-primas, processos, qualidade de produto, normas técnicas e especificações, e larga experiência em resolver problemas de "chão de fábrica”. O PRUMO está atuando, nesta primeira fase, junto ao setor de transformação de plásticos

\section{Qual é o principal objetivo do projeto PRUMO?}

Resolver problemas de produção relacionados com matérias-primas, equipamentos, ferramental, processos e qualidade dos produtos, prestando consultoria tecnológica às micro e pequenas empresas que a necessitem, melhorando sua pro- dutividade, qualidade e patamar tecnológico de seu pessoal técnico. Este trabalho é realizado através da prestação de serviços tecnológicos na área produtiva, ensaios de laboratório e treinamento do pessoal técnico junto às suas máquinas industriais e também junto aos equipa- atingidas pelo projeto em função deste montante?

Os recursos financeiros alocados no projeto PRUMO para o setor de transformação de plástico foram provenientes de todas as entidades envolvidas, no seguinte montante:

\begin{tabular}{|c|c|c|}
\hline FAPESP & $\begin{array}{l}\text { Veículos e adaptações (2) } \\
\text { Equipamentos de laboratório (2) }\end{array}$ & $\begin{array}{l}\mathrm{R} \$ 95.000,00 \\
U \$ 248.000,00\end{array}$ \\
\hline SEBRAE-SP & $\begin{array}{l}\text { Atendimentos tecnológicos } \\
\text { Outras Despesas }\end{array}$ & $\begin{array}{l}R \$ 700.000,00 \\
R \$ 167.000,00\end{array}$ \\
\hline IPT & $\begin{array}{l}\text { Contrapartida } \\
\text { (Central de operações, treinamento } \\
\text { das equipes) }\end{array}$ & $\mathrm{R} \$ 196.000,00$ \\
\hline INP & Contrapartida (divulgação) & $\mathrm{R} \$ 44.000,00$ \\
\hline
\end{tabular}

mentos da Unidade Móvel (Laboratório), no que se refere aos ensaios necessários à avaliação das matérias primas e/ou produção e/ou produtos acabados.

Qual é o montante de recursos destinado ao projeto PRUMO? Quais são as metas a serem
Quais são os principais beneficiados através da implantação do projeto PRUMO? Qual é a expectativa de atendimento aos solicitantes? Qual é o raio de ação deste atendimento?

Os principais beneficiados são os micro e pequenos empresários. A área de atuação do PRUMO, 
prestando atendimentos abrange todo o Estado de São Paulo. Para as regiões afastadas da grande São Paulo, sempre se procura reunir 3 a 4 empresas, em cidades próximas, que necessitem consultoria tecnológica, pois desta forma o tempo e o custo do deslocamento da Unidade Móvel são minimizados.

Quanto à expectativa, está se procurando fazer o diagnóstico (ou visita prévia para levantamento de problemas) da empresa na mes-



Dr. Mazzarella idealizador do Projeto
Que tipo de ensaios são realizados pelas unidades móveis? Como estes ensaios foram definidos durante a elaboração do projeto PRUMO?

Por se tratar de atendimento tecnológico às micro e pequenas empresas do setor de transformação de plásticos, os ensaios realizados pelas unidade móveis são os padronizados para esta área, a saber: Físicos: densidade, ponto de fusão, índice de fluidez, teor de ma semana de sua solicitação, e prestar o atendimento tecnológico em, no máximo, 15 dias após o diagnóstico

\section{Como o beneficiário deve pro-} ceder para participar do projeto PRUMO? Quais são os custos envolvidos? Como eles são orçados?

Para a empresa receber o benefício do custo subsidiado pelo SEBRAE, ela precisa se enquadrar como micro ou pequena empresa ou seja ter menos de 100 funcionários. A inscrição deve ser feita contatando os responsáveis pelo PRUMO, através do telefone (011) 3767-4281. Quanto aos custos, cada atendimento tecnológico está orçado em R \$2.900,00 sendo que o SEBRAE subsidia R\$2.000,00 para as micro e pequena empresas e os R\$900,00 é a contrapartida da empresa em recursos financeiros. inorgânicos e de voláteis e espectroscopia no infravermelho.

Mecânicos: durezas Shore A e $\mathrm{D}$, resistência à tração, flexão, compressão, impacto Izod.

Estes ensaios são os mais usados nos trabalhos do dia a dia das empresas tanto no que se refere à avaliação das matérias-primas, quanto a produtos em processamento e produtos acabados.

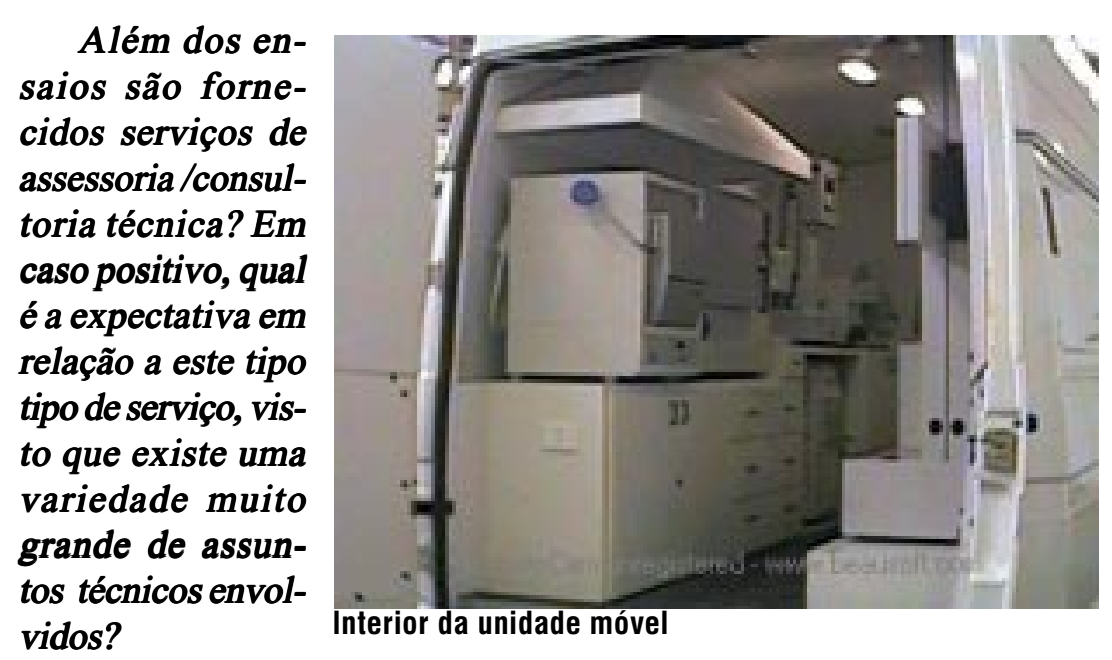

Além dos ensaios citados, o atendimento tecnológico prevê a consultoria técnica no que se refere a estudo e sugestões de alterações no processo produtivo, eventuais trocas de matérias-primas, ajustes em moldes e também ensaios paralelos para acompanhamento e avaliação do processo produtivo.

Durante os atendimentos já efetuados, num total de 36 , foram feitos ajustes de máquinas injetoras, extrusoras, moldes, matériaprima e outros, ajustes estes bem aceitos pelas empresas, que também levaram à melhoria da qualidade de seus produtos finais e da sua produtividade.

Como são realizados determinados ensaios padronizados que exigem condições ambientais especiais, já que os ensaios são realizados em veículos (unidades móveis)? E quanto ao condicionamento padronizado de corposde-prova para determinados ensaios?

As unidades móveis contam com condicionador de ar que permite uma climatização adequada (temperatura e umidade relativa do ar) aos testes mecânicos, de acor- 
do com as normas, e os corpos de ral, por $24 \mathrm{~h}$.

Em casos onde é necessário realizar ensaios utilizando corpos-de-prova moldados em condições padronizadas, como isto é viabilizado?

Quando são necessários corposde-prova com dimensões padronizadas, se o material não for muito rígiprova são condicionados, em ge-
IPT. Quando o material estiver na forma de grânulos, caso a empresa não tenha condições de injetálos, o IPT se propõe a injetar, mas a empresa deve enviar o material também com no mínimo uma semana de antecedência.

É evidente que haverá casos mais complexos em que não será possível fornecer a solução de imediato. Esses casos são encaminhados aos diversos laboratórios do IPT onde os problemas serão tra- sitava, entre outros atributos técnicos, que os mesmos possuíssem características de robustez compatível com a instalação em um veículo. Além disso, houve a preocupação de instalar os equipamentos nos veículos através de dispositivos amortecedores de choques e vibrações, para reduzir ao mínimo os problemas oriundos do constante deslocamento das Unidades Móveis.

As Unidades Móveis estão em circulação há 2 meses e os equipamentos ainda não apresentaram qualquer problema devido ao deslocamento. O único problema encontrado foi com a balança analítica, quando da determinação da densidade, em fábricas com muita trepidação. Neste caso a balança foi retirada da unidade móvel e buscou-se um local adequado ao seu manuseio dentro da própria empresa, inclusive com temperatura do pode-se cortá-los na própria unidade móvel, em um balancim com molde adequado, podendo estes corpos de prova ser produzidos a partir de peças ou placas.

Em casos de materiais de alta rigidez solicita-se ao cliente que nos envie, uma semana antes do atendimento, o material em forma de peças ou placas para que os mesmos sejam usinados no Laboratório de Plásticos e Borrachas do tados com outros recursos e estudados até sua solução final.

\section{Existe alguma inconveniência} em se utilizar laboratórios sobre um Veículo, comparado a um laboratório convencional? Quais são os equipamentos mais sensíveis ao deslocamento constante da unidade móvel?

A especificação dos equipamentos a serem instalados requi- dentro dos padrões exigidos pelas normas.

Outro cuidado adicional diz respeito à freqüência de calibração dos instrumentos. Devido à maior probabilidade de "descalibração" em relação a equipamentos instalados em laboratórios fixos, o período de validade das calibrações foi reduzido à metade para alguns equipamentos e a cerca de $1 / 3$ para outros.

Entrevista elaborada pelo Prof. Dr. Elias Hage Jr, da Universidade Federal de São Carlos, Departamento de Engenharia de Materiais. 